\title{
False history expressed by victims during medico-legal examinations: experience of a Forensic medicine practitioner in Sri Lanka
}

\author{
Senanayake SMHMK..$^{*}$
}

\begin{abstract}
During the medico-legal practice sometimes false history is expressed by victims. Such instances can be divided as false statements related to injuries, events of the incident, sex assault, child abuse and intimate partner violence. Detailed history taking, second history taking following physical examination, collection of information from other sources such as from relations, records of bed head ticket, and police are helpful to obtain true history during reexamination. Medico-legal opinion should be mainly based on evidence such as examination findings and investigation results. False history is one possibility that should be considered before expressing the final medicolegal opinion.
\end{abstract}

Key words: medico-legal examination, clinical history, false statements, re-examination, corroboration, Sri Lanka

\section{Introduction}

Clinical history is very important for the diagnosis of the illness and subsequent clinical management. History expressed by the patient during medico-legal examination is also very important because physical examination, investigations and ultimate medicolegal opinion depend on the history of the patient. False history may lead to false opinion. Forensic medicine practitioner (FMP) is expected to express the ultimate opinion based on history and findings as "findings are compatible with the history, findings are not compatible with the history or history cannot be excluded". Clinicians are well aware about changing history and false history of parents in cases of child abuse. [1] During the medico-legal service over two decades, author had come across several instances where patients made false statements. Such false statements were recognized by the author with the help of three different clues. History documented in the bed head ticket was different from the patient's first history to FMP. When it was informed to the patient, true history was expressed in second occasion. Injury patterns were not consistent with the first history. When patient was asked about discrepancy patient expressed the real history in the

${ }^{1}$ Consultant Judicial Medical Officer, Teaching Hospital Anuradhapura

*Corresponding author: Senanayake SMHMK, Tele:

0094718195569, e-mail address:dilruksena62@yahoo.co.uk second examination. Police, relations and other persons had told a different history to FMP. When patient was informed about the different story, patient told the truth in the second occasion

False histories in medico-legal practice were rare. Histories were confirmed as false only when the patient accepted that first statement is wrong. In mental health practice false complains and false histories are well recognized under three categories as malingering, factitious disorders and feigning. Malingering is intentional production of false or grossly exaggerated physical or mental symptoms, motivated by external incentives. Factitious presentations are intentional production of symptoms that motivated by the desire to assume sick role. Feigning is deliberate fabrication or gross exaggeration of physical or psychological symptoms without any specific motivation. [2]

\section{Different types of false histories of victims-}

All false histories expressed by patients can be divided in to several groups such as in relation to injuries, events of the incident, sex assaults, child abuse cases and intimate partner violence cases. False histories are more encountered in relation to statutory rapes, child abuse cases, intimate partner violence cases and torture cases than other forensic instances.

(A) False statements related to injuries were found rarely. Injuries due to falls, skin rashes, self-inflicted injuries, injuries inflicted by friendly hands were shown as injuries due to assaults. Old injuries were 
shown as new injuries resulted from recent assaults. Bony nodules of the skull had been shown as contusions after assaults.

(B) False statements related to the events of the incidents were in different forms. Sometimes patients expressed a part of the clinical history. Sometimes victims had not disclosed their part of contribution such as provocation for the fight, patient assaulted back or patient had defended. When the other party was examined, unsaid part of history was revealed. Sometimes patients had denied of significant diagnosed illness like diabetes, epilepsy, alcohol dependence and mental illnesses contributed for the incident. However, the entries of bed head tickets and diagnosis cards had shown those significant past illnesses. Drunken riders of motor bicycles told they were pillion riders. When police inquired from "said to be riders" the real riders were discovered.

Significant number of patients claimed that they lost consciousness after the trauma. But detailed history taking about what happened step by step showed victims could remember everything and the loss of consciousness could be excluded. People know that loss of consciousness is a serious event. To make the incident in to a serious nature people complains loss of consciousness.

Examinees commonly denied consumption of alcohol prior to the incident. But bed head ticket and transfer forms from local hospital showed alcohol smell of the patient. On contrary to victims, majority of accused produced by the police denied the allegation of assault, rape or murder. They had said allegations are false.

Most of the victims of police assaults denied police assault. But physical examination showed multiple injuries. When inquired about the reasons for injuries they disclosed about the assaults. They told that they did not want to disclose about police assault due to fear of further harassments by police. Some prisoners showed injuries consistent with self-inflicted injury pattern and alleged about assault by prison officers.

(C) False statements related to sex assaults were not uncommon in certain types of sex assaults. In underage (below 16 years) statuary rape cases, some females denied sexual activities. But genital examinations showed hymeneal tears. After inquired about the reason for hymeneal tears underage patients disclosed about sexual activities. Rarely in alleged rape cases female accepted consensual sex at the end of history taking. They told that rape complain was made because of discovery of sexual relationship by another person. Several alleged rape victims explained during the history taking about going to a hotel room with the perpetrator. Sometimes victims of alleged rapes cases accepted love affairs with the perpetrator during the latter part of history taking which was hidden at the beginning of the history. History of loss of consciousness at the time of sex assault is not rare. At the end of medico-legal examination some accepted that there were no loss of consciousness and they could remember the sexual activity. Few other victims who had not any evidence of sexual activity accepted that allegations were false. In one occasion female victim showed bodily injuries and complained about a rape incident. Court trail revealed that injuries were inflicted by father after discovery of consenting sex of the daughter and her lover who is a married man.

(D) False statements related to child abuse cases were found in several instances. Some child victims had denied any sexual assault at the begging of the medico-legal examinations. After discovering the hymeneal tears those children explained the sex activities of relations and requested not to send them to the prison. In some cases, even though children denied sexual abuse by family members to the FMP, police had discovered eye witnesses of the sex assaults or witnesses who had listened to the description of sex activities by the children. One occasion mother complained about child abuse by father and requested to send the child to an orphanage but child did not know anything about the sexual activity.

(E) False history related to intimate partner violence cases were common. Commonly wives had denied assaults by husbands to FMP and told they do not want to punish husbands. But they have disclosed the real history to clinicians. Sometimes wives requested not to take legal actions because they do not want further assaults by husbands. One victim complained about chronic anal abuse by husband after filling a divorce case, but there were no physical evidence. Later she accepted about false history.

\section{Discussion}

History of the medico-legal report is very important in the court trial because it would be corroborated with the patient's oral evidence to find consistency. When examinee is found to have lied or incompatible history teller he or she becomes unreliable witness in the court trial.

False statements could be completely false statement, part false and part true statement or part omitted statement. Incomplete history may not be intentional as false history because it may be due to repeated history telling to police, admission officer and ward staff prior to the medico-legal examination. FMP are advised to be aware that further disclosure may occur after the examination of child victims. [3] 
History of the patient should not be suspected as false without reasonable evidence. Author had seen several occasions where all the involved clinicians had suspected innocent patients or guardians when they explained the situation correctly. Perineal groove was suspected as a case of child rape. [4] Abnormal hand movements due to thalamic infarction after road traffic accident was suspected as malingering.

False histories are given by patients during medicolegal examinations for various reasons such as to protect the accused, to punish an enemy, to obtain compensation and for self-protection. [5] Very importantly there is a reason. If FMP suspects about false history, he also should explore the reason for it. [6]

Sometimes victims of child abuse, statutory rape and torture deny any harm. In child abuse and statutory rape cases, victims express negative history to protect the perpetrators. In torture cases victims do not want further harassments. Therefore, in clinical practice, irrespective of negative history, complete physical examination is performed to exclude any injury in alleged child abuse cases and alleged torture cases.

"Victim is lying" is a common defense in the trial. Medico-legal practitioners should respect that version of the defense counsels because in medico-legal examinations it had been observed. Because people are legally oriented and lie on advise of others or on their own to make the allegation strong. In real medico-legal practice very few histories can be clearly identified as wrong by FMP. Lot of false statements are partly correct and partly wrong. Some parts are added or removed for benefit. Criminal law had addressed various concepts of deception. Deception is defined as the communication of a message that is intended to cause a person to believe something untrue. False statements or deceptions could be a lie, misleading statement or false denial. [7]

Opinion of FMP should be mainly based on facts (physical findings and investigation results) he had discovered. Medico-legal examination soon after the admission to the hospital and re-examination before discharge is the best medico-legal practice to detect more physical evidence and collect reliable history. When false history is suspected FMP can explore the history again, discuss with the clinician, police or family members to collect more information.

If FMP suspects false statement, the patient should be referred for psychological examination. Child psychologists are well aware of concepts of indoctrination, suggestion, fantasy, delusion, misinterpretation, miscommunication, innocent lying, deliberate lying, confabulation, pseudo logiaphantastica, over stimulation, group contagion and perpetrator substitution. [4] Forensic Psychiatrists and forensic psychologists use various methods of clinical examinations to detect reliability of the patient such as eye contact, mood, facial appearance, consistency of the story. Even in the court trails, the manner in which the evidence is presented is usually heavily relied upon by judges. Not only forensic psychiatry but training in psychology and psychiatry during the postgraduate training in clinical forensic medicine will be a great strength for FMP for history taking, examination and formation of opinion.

\section{Conclusion}

Sometimes patients lie to FMP for various reasons such as for self-protection, to protect perpetrator or punish an enemy. Detailed history taking, second history taking following physical examination, collection of information from other sources such as clinicians, relations, records of bed head ticket, and police, are helpful to obtain true history during reexamination. Medico-legal opinion should be mainly based on facts (clinical examination findings and investigation results). Even though false history is rare, it is one possibility that should be considered before expressing the final medico-legal opinion in a trial.

\section{References}

1. Werner U. Spitz. Spitz and Fisher's Medicolegal Investigation of Death.2006. 4th edition. Charles C Thomas; New York.pp-357-361

2. Richard Rogers. Clinical assessment of malingering and deception.2008. $3^{\text {rd }}$ edition. The Gulford press; New York. pp-3-8

3. McLay WDS. Clinical Forensic Medicine.2009. $3^{\text {rd }}$ edition. Cambridge University Press; New York. p 128

4. Senanayake, SMHMK, Tennakoon UAK. "Perinea groove leading to a suspicion of child sexual abuse." Ceylon Medical Journal. 2014: Vol 59(4) 147-148

5. William Bernet. False Statements and the Differential Diagnosis of Abuse Allegations. Journal of the American Academy of Child \& Adolescent Psychiatry. September 1993; 32(5): 903-910

6. Judy Zaparniuk, John C. Yuille, Steven Taylor. Assessing the credibility of true and false statements. International Journal of Law and Psychiatry. Summer 1995; 18 (3): 343-352

7. Stuart P. Green. Lying, Misleading, and Falsely Denying: How Moral Concepts Inform the Law of Perjury, Fraud, and False Statements. Hastings Law Journal. 2001;53:3642 